\title{
PEMANFAATAN TITONIA SEBAGAI PUPUK ALTERNATIF DAN BAHAN SUBTITUSI PUPUK N, P, DAN K, BAGI PADI SAWAH INTENSIFIKASI YANG DIBERI P SECARA STARTER
}

\author{
Gusnidar* \\ *)Prodi Ilmu Tanah Fakultas Pertanian Universitas Andalas Padang, \\ Sumatera Barat, Indonesia 25163 \\ Email: gusnidar.a02@gmail.com ; Mobile; +6281363389265
}

\begin{abstract}
Abstrak
Penelitian bertujuan menentukan interaksi antara Titonia $(\mathrm{Tt})$ dan takaran pupuk $\mathrm{P}$-starter $\left(\mathrm{P}_{-s}\right)$ terhadap produksi padi sawah intensifikasi. Penelitian berlokasi di Kenagarian Sicincin Kabupaten Padang Pariaman Sumatera Barat. Percobaan berbentuk faktorial $2 \times 3$ dalam rancangan petak terbagi (RPT) dengan 3 kelompok. Petak utama adalah dosis $\mathrm{Tt}$, Urea, dan $\mathrm{KCl}, \mathrm{T}_{0}=0,0$ tonha $^{-1}$ $\mathrm{Tt}+200 \mathrm{kgUrea}+75 \mathrm{kgKCl}\left(\right.$ Urea dan $\mathrm{KCl}$ rekomendasi $=\mathrm{R}$ ); $\mathrm{T}_{1}=5$, tonha ${ }^{-1} \mathrm{Tt}+100 \mathrm{kgUrea}$ (Urea 50\% $\mathrm{R})$, tanpa KCl. Anak petak adalah dosis $\mathrm{P}_{-\mathrm{s}} ; \mathrm{P}_{0}=0 \mathrm{~kg} \mathrm{P}$ ha- ${ }^{-1} \mathrm{P}_{3}=3 \mathrm{~kg} \mathrm{P} \mathrm{ha}^{-1} ; \mathrm{P}_{6}=6 \mathrm{~kg} \mathrm{P}$ ha-1. Dibuat pula 3 petak kontrol menurut tradisi petani (200kg SP-36ha-1, dan 200kg Ureaha ${ }^{-1}$ ). Pengamatan dilakukan terhadap tanah dan tanaman, data tanaman diuji $\mathrm{F}$, dan dilanjutkan dengan Uji BNT taraf 5\%. Hasil penelitian menunjukkan bahwa $\mathrm{Tt}$ dapat digunakan sebagai pupuk alternatif untuk menghemat penggunaan pupuk buatan (PB) berupa pupuk N (Urea), pupuk P (SP36 atau TSP), dan pupuk $\mathrm{K}(\mathrm{KCl})$ untuk tanaman padi sawah intensifikasi. Penggunaan Tt sebanyak 5,0ton kering ha ${ }^{-1}$ dapat mengurangi dosis PB hingga 50\% pupuk N (100kg Urea), $162 \mathrm{~kg}$ SP-36, dan $100 \%$ pupuk $\mathrm{K}(75 \mathrm{~kg} \mathrm{KCl})$ dengan hasil gabah sekitar 6,0 ton ha-1 (kadar air $14 \%$ ). Pemberian Tt sebagai pupuk alternatif untuk mensubtitusi 50\% penggunaan pupuk $\mathrm{N}$, dan $100 \%$ pupuk $\mathrm{K}$, dan mengurangi penggunaan pupuk $\mathrm{P}(81 \%)$ sehingga dapat menghemat biaya produksi. Dengan demikian $\mathrm{Tt}$ dapat direkomendasikan sebagai pupuk alternatif untuk mensubtitusi sekitar 50\% penggunaan pupuk N, P, dan K pada tanah sawah intensifikasi.
\end{abstract}

Kata kunci: Pupuk alternatif, pupuk buatan, sawah intensifikasi, titonia

(C) 2017 Gusnidar Gusnidar

\section{PENDAHULUAN}

Kadar Fospor (P) tanah sawah intensifikasi sudah sangat tinggi, dan tidak seimbang lagi dengan unsur hara lainnya, termasuk bahan organik tanah (BOT). Oleh sebab itu, diperlukan input yang mampu meningkatkan BOT, sekaligus mampu meningkatkan dan menyeimbangkan hara dalam tanah. Salah satu bahan yang dapat digunakan untuk tujuan tersebut adalah $\mathrm{Tt}$. Tumbuhan semak $\mathrm{Tt}$ banyak ditemukan di lahan terlantar, pinggiran jalan dan pinggiran saluran air, mulai dataran rendah sampai dataran tinggi. Hasil analisis Gusnidar dan
Prasetyo (2008) Tt mengandung hara 3,43\% N; $0,31 \% \mathrm{P} ; 4,16 \% \mathrm{~K} ; 1,14 \% \mathrm{Ca} ; 0,78 \% \mathrm{Mg}$; lignin $16,90 \%$ lignin; $52,99 \%$ selulosa, dan mengandung asam organik (AO) dalam bahan segarnya sebesar 7,36 $\mathrm{mgkg}^{-1}$ asam benzoat; $13,90 \mathrm{mgkg}^{-1}$ asam propionat; $118,75 \mathrm{mgkg}^{-1}$ asam sitrat, dengan ratio $\mathrm{C} / \mathrm{N} 13,96$ serta ratio C/P 154,50.

Gusnidar, Hakim, dan Prasetyo (2010) menyatakan bahwa pada tanah sawah dalam kondisi lembab, pemberian $\mathrm{Tt}$ tidak membahayakan bibit padi umur muda, sehingga layak digunakan sebagai $\mathrm{BO}$ dan pengganti sebagian PB. Hal ini senada dengan pendapat 
Ponnamperuma (1985) bahwa keracunan AO pada tanaman padi jarang terjadi pada tanah mendekati netral. Gusnidar, dan Prasetyo (2008) menulis bahwa pemberian $\mathrm{Tt}$ setara 7,5 tonha $^{-1}$ diiringi $P_{-s} 3,50$ kgha $^{-1}$ memberikan hasil gabah maksimum $\left(132,82\right.$ gpot $\left.^{-1}\right)$ di rumah kaca, namun takaran $\mathrm{Tt}$ 7,5 tonha $^{-1}$ tidak berbeda nyata dengan 5,0 tonha- ${ }^{-1}$ terhadap hasil gabah. Berdasarkan hasil tersebut, maka dalam percobaan ini digunakan takaran $\mathrm{Tt}$ 5,0 tonha ${ }^{-1}$. Tujuan penelitian adalah untuk menentukan interaksi antara $\mathrm{Tt}$ dan takaran pupuk $\mathrm{P}_{\text {-s }}$ terhadap produksi padi di sawah intensifikasi.

\section{BAHAN DAN METODA}

Percobaan berbentuk faktorial $2 \times 3$ dalam RPT dengan 3 kelompok. Petak utama adalah dosis $\mathrm{Tt}$, Urea, dan $\mathrm{KCl}, \mathrm{T}_{0}=0,0$ ton $\mathrm{Tt}$ $\mathrm{ha}^{-1}+200 \mathrm{~kg}$ Urea $+75 \mathrm{~kg} \mathrm{KCl}$ (Urea dan $\mathrm{KCl}$ rekomendasi $=\mathrm{R}) ; \mathrm{T}_{1}=5,0$ ton $\mathrm{Tt} \mathrm{ha}^{-1}+100 \mathrm{~kg}$ Urea (Urea $50 \% \mathrm{R}$ ), tanpa $\mathrm{KCl}$. Anak petak adalah dosis $\mathrm{P}$-starter; $\mathrm{P}_{0}=0 \mathrm{~kg} \mathrm{P}$ ha ${ }^{-1} ; \mathrm{P}_{3}=3 \mathrm{~kg}$ $\mathrm{P} \mathrm{ha}^{-1} ; \mathrm{P}_{6}=6 \mathrm{~kg} \mathrm{P} \mathrm{ha}^{-1}$.

Persemaian basah disiapkan 21 hari sebelum tanam, umur 10 hari bibit dipupuk dengan Urea $\left(20 \mathrm{gm}^{-1}\right)$. Titonia diambil dari pinggiran saluran air dekat lokasi percobaan. Titonia dicincang (sekitar $3 \mathrm{~cm}$ ), ditetapkan kadar airnya, dan ditimbang sebanyak $60 \mathrm{~kg}$ petak $^{-1}$ (setara $12 \mathrm{~kg}$ bobot kering). Titonia ditaburkan pada petak percobaan, kemudian diaduk dengan cangkul dan diinjak-injak dengan kaki, diinkubasi selama 3 minggu.

Pupuk $\mathrm{P}_{\text {-s }}$ saat tanam sesuai perlakuan $\left(0,3\right.$, dan $\left.6 \mathrm{~kg} P \mathrm{ha}^{-1}\right)$. Teknik pemberian pupuk $\mathrm{P}$ secara starter (persiapan lumpurnya disiapkan sehari sebelum tanam dalam ember plastik, dan pupuk dilarutkan dalam plastik, diperam satu malam, kemudian dicampurkan dengan lumpur yang telah disiapkan, sesuai dengan perlakuan. Pupuk $\mathrm{KCl}$ dan setengah dosis Urea diberikan 2 Minggu Setelah Tanam (MST) dan Urea separoh dosis lagi pada 6 MST. Dosis KCl, Urea, pupuk P dan Tt yang diberikan disajikan dalam Tabel 1. Untuk perlakuan menurut cara petani diberikan $200 \mathrm{~kg}$ Urea dan $200 \mathrm{~kg}$ SP-36 ha-1 (setara 240gpetak ${ }^{-1}$ ) tanpa pupuk $\mathrm{KCl}$.

Tabel 1. Takaran titonia dan pupuk buatan yang diberikan tiap unit percobaan

\begin{tabular}{|c|c|c|c|c|c|}
\hline \multirow[t]{2}{*}{$\begin{array}{l}\text { Titonia } \\
\text { ton } \text { ha }^{-1}\end{array}$} & \multirow[t]{2}{*}{$\begin{array}{l}\text { Urea } \\
\mathrm{kg} \mathrm{ha}^{-1}\end{array}$} & \multirow[t]{2}{*}{$\begin{array}{c}\mathrm{KCl} \\
\mathrm{kg} \mathrm{ha}^{-1}\end{array}$} & \multirow[t]{2}{*}{$\begin{array}{l}\text { Takaran P } \\
\mathrm{kg} \mathrm{ha}^{-1}\end{array}$} & \multicolumn{2}{|c|}{$\begin{array}{c}\text { Hemat pupuk } \\
\text { buatan }\left(\mathrm{kg} \mathrm{ha}^{-1}\right)^{*}\end{array}$} \\
\hline & & & & $\begin{array}{l}\text { dari dosis } \\
\text { rekomendasi }\end{array}$ & $\begin{array}{c}\text { dari dosis } \\
\text { petani (kontrol) }\end{array}$ \\
\hline 0,0 & 200 & 75 & 0 & $50 \mathrm{SP}-36$ & 200 SP-36 \\
\hline 0,0 & 200 & 75 & 3 & 31 SP-36 & 181 SP-36 \\
\hline 0,0 & 200 & 75 & 6 & $12 \mathrm{SP}-36$ & 162 SP-36 \\
\hline 5,0 & 100 & 0 & 0 & $\begin{array}{l}100 \text { Urea, } 75 \mathrm{KCl}, 50 \\
\text { SP-36 }\end{array}$ & $\begin{array}{l}100 \text { Urea, } \\
200 \text { SP-36 }\end{array}$ \\
\hline 5,0 & 100 & 0 & 3 & $\begin{array}{l}100 \text { Urea, } 75 \mathrm{KCl} \\
31 \mathrm{SP}-36\end{array}$ & $\begin{array}{l}100 \text { Urea, } \\
181 \text { SP-36 }\end{array}$ \\
\hline 5,0 & 100 & 0 & 6 & $\begin{array}{l}100 \text { Urea, } 75 \mathrm{KCl} \\
12 \mathrm{SP}-36\end{array}$ & $\begin{array}{l}100 \text { Urea, } \\
162 \text { SP-36 }\end{array}$ \\
\hline $\begin{array}{l}\text { Cara } \\
\text { petani }\end{array}$ & 200 & 0 & $31,44^{* *}$ & 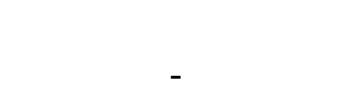 & 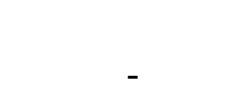 \\
\hline
\end{tabular}


Penanaman dilakukan pada umur bibit 21 hari. Benih setelah dicabut dari persemaian, perakarannya dibersihkan dari lumpur dan diperas. Tujuannya agar larutan pupuk $\mathrm{P}_{-\mathrm{s}}$ mudah menempel pada perakaran. Saat tanam, kondisi air sawah dalam keadaan macakmacak. Bibit yang telah disiapkan direndam dalam larutan pupuk bercampur lumpur sesuai perlakuan, selama 10 menit. Setelah itu bibit ditanamkan satu batang tiap titik tanam dengan jarak $25 \mathrm{~cm} \times 25 \mathrm{~cm}$. Setelah tanam, kondisi air sawah dipertahankan dalam keadaan lembab, kecuali pada saat membersihkan gulma. sawah digenangi, agar lebih mudah dalam mencabutnya. Selanjutnya, air dipertahankan dalam keadaan lembab sampai akhir masa vegetatif. Untuk periode berikutnya sampai seminggu menjelang panen sawah digenangi dengan ketinggian air sekitar $5 \mathrm{~cm}$ dari permukaan tanah. Seminggu akan panen sawah dikeringkan.
Pengamatan ciri kimia tanah sawah sesudah inkubasi $\mathrm{Tt}$, meliputi $\mathrm{pH} \mathrm{H}_{2} \mathrm{O}$ dan $\mathrm{Eh}$ (1:2); $\mathrm{N}_{\text {-tot. }}, \mathrm{C}_{-}$-org., $\mathrm{C} / \mathrm{N}, \mathrm{P}_{\text {-Bray-2}}, \mathrm{K}_{- \text {-dd, }}, \mathrm{Na}_{\text {-dd }}, \mathrm{Ca}_{-}$ dd, $\mathrm{Mg}_{\text {-dd, }}$ kapasitas tukar kation (KTK), $\mathrm{Fe}_{\text {-dd, }}$

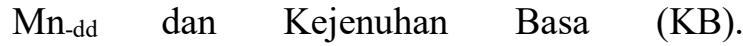
Pengamatan tanaman meliputi jumlah anakan total, jumlah malai, bobot kering jerami, bobot gabah bernas, dan bobot 1000 biji. Data tanaman dianalisis ragam. Untuk faktor yang berpengaruh nyata dilanjutkan dengan uji BNT pada taraf nyata 5\%.

\section{HASIL DAN PEMBAHASAN} Analisis tanah.

Inkubasi dan dosis $\mathrm{Tt}$ tidak mengubah Eh dan $\mathrm{pH}$ tanah, tetapi dapat meningkatkan $\mathrm{C}_{\text {-org., }} \mathrm{N}_{\text {-tot., }} \mathrm{P}_{\text {-Bray }}$, $\mathrm{K}_{\text {-dd }}, \mathrm{Na}_{\text {-dd }}, \mathrm{Ca}_{\text {-dd }}, \mathrm{Mg}_{\text {-dd }}, \mathrm{KB}$ dan KTK tanah serta menurunkan $\mathrm{Fe}_{\text {-dd }}$ dan $\mathrm{Mn}_{\text {-dd. }}$ (Tabel 2).

Tabel 2. Hasil analisis tanah sawah intensifikasi Sicincin setelah diinkubasi dengan titonia

\begin{tabular}{|c|c|c|c|c|}
\hline Parameter & Satuan & Tanpa titonia & Titonia & 5,0 ton $\mathrm{ha}^{-1}$ \\
\hline $\mathrm{pH} \mathrm{H}_{2} \mathrm{O}(1: 2)$ & & 6,26 & & 7,06 \\
\hline Eh $\quad(1: 2)$ & $(\mathrm{mV})$ & -124 & & -129 \\
\hline $\mathrm{N}$-total & $(\%)$ & 0,51 & & 0,55 \\
\hline C-Organik & $(\%)$ & 5,01 & & 5,18 \\
\hline $\mathrm{CN}^{-1}$ & & 8,68 & & 8,85 \\
\hline $\mathrm{P}_{\text {-Bray } 2}$ & $\left(\mathrm{mg} \mathrm{kg}^{-1}\right)$ & 227,61 & & 251,97 \\
\hline$K_{-d d}$ & me $(100 \mathrm{~g})^{-1}$ & 1,93 & & 2,27 \\
\hline $\mathrm{Na}_{-\mathrm{dd}}$ & me $(100 \mathrm{~g})^{-1}$ & 3,19 & & 3,28 \\
\hline $\mathrm{Ca}$-dd & me $(100 \mathrm{~g})^{-1}$ & 5,64 & & 5,78 \\
\hline $\mathrm{Mg}_{-\mathrm{dd}}$ & me $(100 \mathrm{~g})^{-1}$ & 1,76 & & 1,78 \\
\hline KTK & me $(100 \mathrm{~g})^{-1}$ & 43,45 & & 47,51 \\
\hline $\mathrm{Fe}_{- \text {-dd }}$ & $\left(\mathrm{mg} \mathrm{kg}^{-1}\right)$ & 23,51 & & 20,87 \\
\hline $\mathrm{Mn}_{\text {-dd }}$ & $\left(\mathrm{mg} \mathrm{kg}^{-1}\right)$ & 13,17 & & 7,72 \\
\hline KB & $(\%)$ & 28,81 & & 28,23 \\
\hline
\end{tabular}

Nilai Eh sedikit menurun dan nilai $\mathrm{pH}$ meningkat menjadi netral $(7,06)$, namun nilai Eh masih di bawah $-130 \mathrm{mV}$. Pada nilai Eh tersebut, AO intermediet dalam keadaan labil (Patrick dan Reddy, 1978) dan memungkinkan reduksi ion ferri menjadi ion ferro. Akibatnya terjadi penurunan $\mathrm{Fe}_{\text {-dd }}$ sebesar $2,64 \mathrm{mgkg}^{-1}$, dan $\mathrm{Mn}_{\text {-dd }}$ sebesar $5,45 \mathrm{mgkg}^{-1}$. Kation-kation basa $(\mathrm{K}, \mathrm{Na}, \mathrm{Ca}$, dan $\mathrm{Mg})$ yang dapat dipertukarkan juga meningkat bila dibandingkan dengan petakan yang tidak diberi Tt.

Peningkatan $\quad \mathrm{K}_{\text {-dd }}$ sebesar 0,34 me $(100 \mathrm{~g})^{-1}$, dan $\mathrm{N}_{\text {-tot }}$ sebanyak $0,04 \%$, jelas akibat sumbangan $\mathrm{K}$, dan $\mathrm{N}$ dari Tt. Pemberian setara 5,0tonha ${ }^{-1}$ bobot kering $\mathrm{Tt}$ telah membawa $\mathrm{N}$ dan $\mathrm{K}$, sebesar $171,5 \mathrm{~kg} \mathrm{~N}$, dan $208 \mathrm{~kg} \mathrm{~K}$ (jika dikonversikan ke dalam bentuk $\mathrm{PB}$, jumlahnya sama dengan $381 \mathrm{~kg}$ Urea dan $835,46 \mathrm{~kg} \mathrm{KCl}$ ). Jumlah tersebut telah melebihi banyaknya $\mathrm{N}$ dan $\mathrm{K}$ yang terbawa 
oleh Urea dan $\mathrm{KCl}$ menurut dosis rekomendasi. Namun, hara dalam $\mathrm{Tt}$ lebih lambat tersedia dibanding PB, sehingga dalam penelitian ini dicoba menggantikan 50\%.

Peningkatan kadar $\mathrm{C}_{\text {-org. }}$ sebesar $0,18 \%$ juga akibat diberi $\mathrm{Tt}$. Walaupun nilai $\mathrm{C}_{\text {-org. }}$. tanah telah tinggi $(5,01 \%)$, namun tujuan utama dari percobaan ini adalah untuk menggantikan sebahagian $\mathrm{PB}$ dengan hara dalam $\mathrm{Tt}$, di samping juga mempertahankan kadar BOT. Asam organik diharapkan dapat melarutkan Ptanah yang telah sangat tinggi, sehingga input pupuk $\mathrm{P}$ juga dapat dikurangi, bahkan kalau memungkinkan selama waktu tertentu tidak diberikan pupuk $\mathrm{P}$.

Penggunaan $\mathrm{Tt}$ sebagai $\mathrm{BO}$ dan pengganti sebagian hara dari $\mathrm{PB}$ telah mampu meningkatkan kadar P-tanah sawah intensifikasi 24,36 $\mathrm{mgkg}^{-1}$ (Tabel 1). Kenaikkan ketersediaan $\mathrm{P}$, dapat berasal dari $\mathrm{P}$ yang terlepas dari hijauan $\mathrm{Tt}$ selama proses dekomposisi, dan dapat pula berasal dari pelarutan P-tanah oleh AO hasil dekomposisi $\mathrm{Tt}$ dan BO lain selama inkubasi. Gusnidar et al (2010) menyatakan bahwa AO seperti asam asetat, benzoat, galat, malat, salisilat, sitrat, tartarat yang terdapat dalam $\mathrm{Tt}$ telah berperan dalam melepaskan P terikat pada tanah sawah intensifikasi. Peningkatan ketersediaan $P$ akibat pemberian hijauan $\mathrm{Tt}$, diasumsikan $\mathrm{Tt}$ mampu menyediakan $\mathrm{P}$ awal pertumbuhan tanaman padi, sehingga pemupukan $P$ bisa diminimalkan.
Penggenangan juga meningkatkan ketersediaan P. Menurut De Datta (1981), mobilitas $\mathrm{P}$ yang tinggi pada proses penggenangan, mampu mensuplai kebutuhan $\mathrm{P}$ tanaman padi. Tanah sawah intensifikasi yang telah mengandung $\mathrm{P}$ cukup tinggi, diharapkan dapat memenuhi kebutuhan hara tanaman padi walaupun input pupuk $\mathrm{P}$ diminimalkan. Berdasarkan hasil-hasil penelitian dari berbagai lokasi di Indonesia, pada lahan sawah intensifikasi memang tidak diperlukan penambahan pupuk $\mathrm{P}$ tiap musim tanam (Puslittanak, 1995; Taher, 1999). Oleh karena itu, paket pemupukan yang selama ini telah direkomendasikan, terutama pupuk N, P, dan K, perlu dikaji kembali.

Peningkatan KTK sebesar 4,06 me $(100 \mathrm{~g})^{-1}$ pada tanah yang diberi $\mathrm{Tt}$, juga disebabkan oleh Tt mengandung AO. Asamasam organik mempunyai gugus hidroksil dan fenol yang dapat berfungsi sebagai tapak jerapan. Nilai KTK tanah merupakan sifat kimia yang sangat erat hubungannya dengan ketersediaan hara bagi tanaman. Tanah dengan KTK tinggi mampu menjerap dan menyediakan unsur hara lebih baik daripada tanah dengan KTK rendah. Dengan demikian, penambahan $\mathrm{Tt}$ mampu memperbaiki ketersediaan hara tanah, dan diharapkan dapat memberikan pertumbuhan tanaman padi yang lebih baik. Peningkatan kadar hara juga sejalan dengan perubahan nilai $\mathrm{pH}$ dan $\mathrm{Eh}$ tanah (Tabel 3).

Tabel 3. Rata-rata nilai Eh dan $\mathrm{pH}$ tanah sawah intensifikasi Sicincin 7 MST

\begin{tabular}{|c|c|c|c|c|c|}
\hline \multirow[t]{2}{*}{ Titonia (ton $\mathrm{ha}^{-1}$ ) } & \multicolumn{2}{|c|}{ Pupuk buatan $\left(\mathrm{kg} \mathrm{ha}^{-1}\right)$} & \multicolumn{3}{|c|}{ P-starter $\left(\mathrm{kg} \mathrm{ha}^{-1}\right)$} \\
\hline & Urea & $\mathrm{KCl}$ & 0 & 3 & 6 \\
\hline & & & \multicolumn{3}{|c|}{ Nilai Eh } \\
\hline 0.0 & 200 & 75 & 55,11 & 39,83 & 47,51 \\
\hline 5,0 & 100 & 0 & 41,76 & 38,32 & 46,06 \\
\hline \multirow{2}{*}{\multicolumn{3}{|c|}{$(200 \mathrm{~kg}$ Urea $+200 \mathrm{~kg} \mathrm{SP}-36)$}} & \multirow{2}{*}{\multicolumn{3}{|c|}{$\begin{array}{l}43,68 \\
\quad \text { Nilai } \mathrm{pH}\end{array}$}} \\
\hline & & & & & \\
\hline 0.0 & 200 & 75 & $6,64 \mathrm{n}$ & $6,66 \mathrm{n}$ & $6,48 \mathrm{n}$ \\
\hline 5,0 & 100 & 0 & $6,67 \mathrm{n}$ & $6,97 \mathrm{n}$ & $6,61 \mathrm{n}$ \\
\hline \multicolumn{3}{|c|}{ Cara petani (200 kg Urea + 200 kg SP-36) } & & $6,79 \mathrm{n}$ & \\
\hline
\end{tabular}

$\mathrm{n}=$ netral 
Bila dibandingkan dengan input Urea dan $\mathrm{KCl}$ menurut rekomendasi umum, maka dapat dinyatakan bahwa $\mathrm{Tt}$ mampu menggantikan sebagian hara yang berasal dari $\mathrm{PB}$, yaitu sebanyak $100 \mathrm{~kg}$ Ureaha $^{-1}$ dan $75 \mathrm{~kg}$ $\mathrm{KCl} \mathrm{ha-1}$. Jika dibandingkan dengan tradisi petani, maka $\mathrm{Tt}$ dapat menggantikan $100 \mathrm{~kg}$ Urea dan 16 kg SP-36, karena petani memberi $200 \mathrm{~kg}$ SP-36 tanpa memberikan $\mathrm{KCl}$.

Pemberian 5,0 ton $\mathrm{Tt}$ telah menambah sebanyak $171,50 \mathrm{~kg} \mathrm{~N}$ ha $^{-1}$ ke dalam tanah sawah. Meskipun belum $\mathrm{N}$ yang terdapat dalamTt belum terurai seluruhnya, tetapi bagian yang terurai sudah mencukupi $50 \%$ kebutuhan tanaman padi. Hasil mineralisasi $\mathrm{N}$ pupuk hijau akan menambah ketersediaan $\mathrm{N}$ tanah. Hal ini dapat diperjelas, bahwa hasil pertama dari hasil dekomposi pupuk hijau adalah asam amino, kemudian terbentuk amonium. Ion amonium merupakan Nmineral pertama yang dihasilkan dari proses dekomposisi pupuk hijau yang bisa diserap tanaman. Nitrogen dalam bentuk amonium ini juga merupakan bentuk yang dominan di awal dekomposisi pupuk hijau. Dengan demikian jelaslah bahwa sejumlah $\mathrm{N}$ akan dihasilkan dan tersedia bagi tanaman.

Pemberian 5,0 ton $\mathrm{Tt}$ telah menambah sebanyak $208 \mathrm{~kg} \mathrm{~K} \mathrm{ha-1} \mathrm{ke} \mathrm{dalam} \mathrm{sawah.}$ Walaupun belum semua $\mathrm{K}$ Tt yang diberikan terlepas ke dalam larutan tanah, tetapi sebagian $\mathrm{K}$ yang terurai sudah mencukupi $100 \%$ kebutuhan tanaman padi. Unsur K dari BO terlepas ke dalam larutan tanah selama proses dekomposisi berlangsung. Unsur $\mathrm{K}$ berperan terhadap reaksi enzimatik (ditemukan pada $>50$ enzim), baik secara langsung maupun tidak langsung. Senyawa yang belum terhumifikasi seperti karbohidrat, asam amino, lemak, potein, lignin, asam nukleat, pigmen, dan hormon terdekomposisi, maka $\mathrm{K}$ akan lepas ke larutan tanah, sehingga konsentrasi $\mathrm{K}$ bertambah.

Selanjutnya, pemberian 5,0 ton $\mathrm{Tt}$ dapat menghemat pupuk $\mathrm{P}$ sebanyak $162 \mathrm{~kg}$ SP-36 (25 kg P ha-1). Dari beberapa hasil penelitian pemupukan $P$ di lahan sawah berkadar P-tanah tinggi terutama pada sawah intensifikasi penggunaan $\mathrm{P}$ dapat dikurangi (Adiningsih et al, 1989; Yulnafatmawita et al, 1996; Gusnidar et al, 1997). Dari hasil percobaan Yulnafatmawita et al (1996) di rumah kaca efisiensi penggunaan pupuk (EPP) tertinggi diperoleh pada pemberian $50 \mathrm{~kg}$ TSP ha $^{-1}$. Hal ini disebabkan kadar P-tanah sawah yang digunakan untuk penelitian sudah cukup tinggi (10,93 mg $\mathrm{P} \mathrm{kg}^{-1}$-Bray-2). Namun, pada beberapa lokasi, Suyamto et al (1990) mengemukakan bahwa hasil padi berkurang antara $200-600 \mathrm{~kg}_{\text {gabah }} \mathrm{ha}^{-1}$ bila pupuk P tidak diberikan. Oleh sebab itu, dosis rendah sekitar $50 \mathrm{~kg}$ TSP ha-1 atau penggunaan pupuk $\mathrm{P}_{\text {-s }}$ (4-6 $\mathrm{kgPha}^{-1}$ ) masih perlu diberikan. Pemanfaatan Tt untuk melarutkan P tinggi pada tanah sawah intensifikasi, dan dapat mengurangi PB berupa N, P, dan K adalah jalan keluar dari permasalahan kesulitan dan mahalnya PB.

Dengan demikian, dapat dinyatakan bahwa Tt dapat menggantikan sebagian hara $\mathrm{N}$ dan seluruh hara $\mathrm{K}$ serta mengurangi pupuk $\mathrm{P}$, sehingga dapat mengurangi beban petani dalam pengadaan pupuk. Selain daripada itu, pada sawah intensifikasi yang telah jenuh dengan unsur $\mathrm{P}$, pemberian $\mathrm{Tt}$ mampu meningkatkan ketersediaan $\mathrm{P}$ bagi tanaman padi, seiring dengan peningkatan $\mathrm{N}$ dan $\mathrm{K}$. Dengan demikian input Urea, TSP atau SP-36 dan $\mathrm{KCl}$ akan dapat dihemat. Manfaat lain dari BO berupa $\mathrm{Tt}$ juga akan diperoleh sekaligus, karena $\mathrm{Tt}$ juga mengandung $\mathrm{Ca}(1,14 \%), \mathrm{Mg}$ $(0,78 \%)$ (Tabel 1) dan unsur mikro. Selain daripada itu, khasiat alami dari hormon dan zat pengatur tumbuh yang terdapat dalam BO tidak tergantikan dan tidak terdapat dalam PB sehingga BO ini akan bermanfaat ganda bagi tanaman dan lingkungan.

\section{KESIMPULAN}

1.Titonia dapat digunakan sebagai pupuk alternatif untuk menghemat penggunaan pupuk buatan berupa pupuk N (Urea), pupuk P (SP-36 atau TSP), dan pupuk $\mathrm{K}(\mathrm{KCl})$ untuk tanaman padi sawah intensifikasi. Penggunaan titonia sebanyak 5,0 ton kering ha ${ }^{-1}$ dapat mengurangi dosis pupuk buatan hingga 50\% pupuk $\mathrm{N}$ (100kg Urea), $162 \mathrm{~kg}$ SP-36, dan $100 \%$ pupuk $\mathrm{K}(75 \mathrm{~kg} \mathrm{KCl})$ dengan hasil gabah sekitar 6,0 ton $\mathrm{ha}^{-1}$ (kadar air 14\%). 
2. Pemberian titonia sebagai pupuk alternatif untuk mensubtitusi $50 \%$ penggunaan pupuk $\mathrm{N}$, dan $100 \%$ pupuk $\mathrm{K}$, serta mengurangi penggunaan pupuk $\mathrm{P}(81 \%)$, tentunya akan menghemat biaya produksi.

\section{SARAN}

Titonia dapat direkomendasikan sebagai pupuk alternatif untuk mensubtitusi sekitar $50 \%$ penggunaan pupuk $\mathrm{N}, \mathrm{P}$, dan $\mathrm{K}$ pada tanah sawah intensifikasi.

\section{DAFTAR PUSTAKA}

Adiningsih, J. S. Moersidi., M. Sudjadi, dan A. M. Fagi. 1989. Evaluasi keperluan fosfat pada lahan sawah intensifikasi di Jawa. Dalam Prosiding Lokakarya Nasional Efisiensi Penggunaan pupuk. Cipayung, 21 November 1988. Halaman 63-90.

De Datta, S. K. 1981. Chemical change in submerged rice soil. In Principles and Practice of Rice Production. John Wiley and Sons. Halaman 89145.

Gusnidar, Muhsanati dan Ruhaimah. 1997. Uji level pemupukan $\mathrm{P}$ pada lahan sawah kaya fosfor terhadap produksi tanaman padi (Oryza sativa L). Lembaga Penelitian Unand. Padang. 26 halaman.

Gusnidar dan T. B. Prasetyo. 2008. Pemanfaatan Tithonia diverrsifolia pada tanah sawah intensifikasi yang dipupuk $\mathrm{P}$ secara starter terhadap produksi serta serapan hara $\mathrm{N}, \mathrm{P}$, dan $\mathrm{K}$ tanaman padi. J. Tanah Tropika, 13 (3): 2009-216.
Gusnidar, N. Hakim and T. B. Prasetyo. 2010. Inkubasi tithonia pada tanah sawah terhadap asam-asam organik. J. Solum. VII (1):7-18.

Ponnamperuma. 1985. Chemical Kinetics of wetland rice soil relative to soil fertility. In Wetlands Soils: characterization, classification, and utilization. IRRI. Los Banos. Phillipines. Manila. Halaman 7189.

Puslittanak. 1995. Langkah-langkah antisipasi untuk mengatasi kelangkaan pupuk fosfor MT 1995/1996.

Suyamto, H., H. Sudaryono., H. Kuntyastuti., H. Subagyo., B. Santoso., R. Isgianto., J. Purnomo., dan Sutrisno. 1990. Penelitian effisiensi pemupukan $\mathrm{P}$ pada padi lahan PMK. Bogor, 6-7 Agustus 1990.

Taher, A. 1999. Pemanfaatan timbunan fosfat di lahan sawah. Makalah seminar bulanan Faperta Unand, 10 Mei 1999. Padang. 19 halaman.

Tan, K. H. 1998. Principles of Soil Chemistry. $3^{\text {rd }}$. Marcel Dekker, Inc. N. Y. 521 halaman.

Yulnafatmawita., L. Maira., Gusnidar., Herviyanti., dan N. Hakim. 1996. Peranan ganda ZA sebagai sumber $\mathrm{N}$ dan peningkatan ketesediaan $\mathrm{P}$ pada tanah sawah kaya fosfor yang disidik dengan ${ }^{32} \mathrm{P}$. Lembaga Penelitian Unand. Padang 26 halaman. 